\title{
Identification of a novel human testicular interstitial gene, $R N F 148$, and its expression regulated by histone deacetylases
}

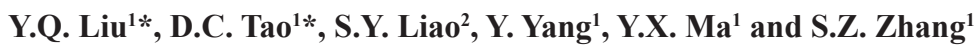 \\ ${ }^{1}$ Department of Medical Genetics, Division of Human Morbid Genomics, \\ State Key Laboratory of Biotherapy, West China Hospital, \\ West China Medical School, Sichuan University, Chengdu, China \\ ${ }^{2}$ Institute of Organ Transplantation, Sichuan Academy of Medical Science, \\ Sichuan Provincial People's Hospital, Chengdu, China \\ *These authors contributed equally to this study. \\ Corresponding authors: Y.Q. Liu / S.Z. Zhang \\ E-mail: yq_liu@scu.edu.cn / szzhang@mcwcums.com
}

Genet. Mol. Res. 12 (3): 4060-4069 (2013)

Received August 22, 2012

Accepted February 4, 2013

Published September 27, 2013

DOI http://dx.doi.org/10.4238/2013.September.27.7

\begin{abstract}
Multiple genes are restrictively expressed in mammalian testicular tissues, and they play important roles in the complex process of spermatogenesis. Investigation of these genes and their expression regulation mechanisms is valuable to elucidate the molecular process of spermatogenesis. In this study, we identified a novel human gene, ring finger protein 148 ( $R N F 148)$ that is abundantly expressed in testes and slightly expressed in pancreas. In situ hybridization analysis showed that RNF148 messenger RNA was mainly present in the interstitial cells of human testicular tissues, and immunohistochemical analysis confirmed protein levels in that location. Treatment with histone deacetylase inhibitor trichostatin A activated the expression of RNF148 messenger RNA in a time- and concentration-dependent manner in HEK293T and HeLa cells, neither of which normally express RNF148. Chromatin immunoprecipitation analysis showed that trichostatin A treatment increased the binding of acetylated histone $\mathrm{H} 3$ to the RNF148 gene
\end{abstract}


promoter. We identified a novel human testicular interstitial gene and observed that histone deacetylases regulate $R N F 148$ expression.

Key words: RNF148; Human testicular interstitial gene; Histone acetylation; Gene expression

\section{INTRODUCTION}

Mammalian spermatozoa development is a complex process that involves the renewal and differentiation of spermatogonia, the meiosis of spermatocytes, and drastic morphological changes from round spermatids to mature spermatozoa (Russell et al., 1990). The formation of a mature spermatozoon also involves the interplay of endocrine factors within the hypothalamic-pituitarygonadal axis and autocrine, paracrine, and juxtacrine interactions between spermatogenic germ cells within the seminiferous tubules and somatic cells such as Leydig and other interstitial cells (Matzuk and Lamb, 2008). An amazingly large number of genes (approximately $4 \%$ of mammalian genes) are specifically expressed in the male germ line (Schultz et al., 2003). The identification of these genes and their biological functions is a considerable challenge that has the potential to be extraordinarily helpful in elucidating the molecular process of spermatogenesis.

In the testis, differential gene expression is achieved through unique chromatin remodeling, transcriptional regulation, post-transcriptional control of messenger RNAs (mRNAs), and the expression of testis-specific genes or isoforms (Kimmins et al., 2004; Kimmins and SassoneCorsi, 2005; Iguchi et al., 2006). Recent studies have revealed that epigenetic events, including DNA methylation and histone modification, are involved in gene expression during spermatogenesis (Khalil et al., 2004; McCarrey et al., 2005; Payne and Braun, 2006; Liu et al., 2010b). DNA methylation at promoter regions is involved in gene silencing. In histone modification, histone tails are post-translationally modified via methylation, acetylation, phosphorylation, ubiquitination, and sumoylation (Fuks, 2005), which alter chromatin structure and allow underlying genes to be activated or repressed. Of these reactions, histone hyperacetylation is generally associated with chromatin decondensation, which increases the accessibility of DNA to binding proteins as well as transcriptional activity, whereas histone hypoacetylation contributes to chromatin condensation and transcriptional repression (Tse et al., 1998; Wang et al., 2001).

In searching for testis-specific genes, we found that a RING-H2 finger protein-coding gene, ring finger protein 148 (RNF148), in the National Center for Biotechnology Information UniGene database (FLJ25788 fis, clone TST06884; GenBank accession No. AK098654). In this study, we determined that RNF148 is mainly present in the interstitial cells of human testicular tissues and investigated the regulation of its expression through epigenetic modification.

\section{MATERIAL AND METHODS}

\section{Human samples}

Normal human testicular and lung tissues were taken from 2 body donors who died in accidents. The tissue was obtained at West China Hospital, Sichuan University, Chengdu, China. Informed consent for the samples was obtained from the relatives of the donors. The present study was authorized by the ethics committee of West China Hospital, Sichuan University, China. 


\section{Cell culture and drug treatment}

HEK293T and HeLa cells were maintained in Dulbecco's modified eagle's medium and RPMI1640 medium, respectively, supplemented with $10 \%$ fetal bovine serum at $37^{\circ} \mathrm{C}$ in a humidified 5\% $\mathrm{CO}_{2}$ incubator. Cells were treated with trichostatin A (TSA; 0, 100, 200, 300, 400, $500 \mathrm{ng} /$ $\mathrm{mL}$ ) for 12, 24, 36, or $48 \mathrm{~h}$. Cells were also treated with $5 \mu \mathrm{M}$ methyltransferase inhibitor 5-aza-dC (AZA, Sigma-Aldrich Co., St. Louis, MO, USA) for 48 h, with AZA replacement every $24 \mathrm{~h}$.

\section{Reversal transcription-polymerase chain reaction (RT-PCR) and quantitative real-time PCR (qRT-PCR)}

A first-strand complementary DNA (cDNA) kit containing cDNA preparations from 16 human tissues (heart, liver, brain, lung, kidney, spleen, pancreas, thymus, small intestine, colon, testis, ovary, prostate, placenta, skeletal muscle, and peripheral leukocytes) was purchased from Clontech (Mountain View, CA, USA). The primers used to amplify RNF148 were 5'-GTGGAGTGTTCGGGAATCAT-3' (forward) and 5'-GCAGCCAGGAAGGTAAATAG-3' (reverse). A 980-bp fragment of glyceraldehyde 3-phosphate dehydrogenase (G3PDH) was coamplified as an internal control with the primers 5'-TGAAGGTCGGAGTCAACGGATTTGGT-3' (forward) and 5'-CATGTGGGCCATGAGGTCCACCAC-3' (reverse).

The primers for qRT-PCR analysis of RNF148 were the same as those for RTPCR, whereas the internal control for normalization was the $\beta$-actin gene with primers 5'-GACGATGCTCCCCGGGCTGTATTC-3' (forward) and 5'-TCTCTTGCTCTGGGCCTCGTCA CC-3' (reverse) as described by Li et al. (2011). qRT-PCR was performed with cDNA using SYBR Premix Ex Taq II (Takara Biotech Co. Ltd., Dalian, China) plus $10 \mathrm{mM}$ corresponding sense and antisense primers. Reactions were run on a Bio-Rad iCycler RT- PCR Detection System (Hercules, CA, USA)using the following parameters: $95^{\circ} \mathrm{C}$ for $1 \mathrm{~min}, 95^{\circ} \mathrm{C}$ for $10 \mathrm{~s}$, and $60^{\circ} \mathrm{C}$ for $30 \mathrm{~s}$ for 40 cycles. Three separate assays were performed in duplicate on each tissue. The threshold values from each run were averaged per tissue. The $\Delta \Delta C T$ method was then applied for data analysis, in which the value of $R N F 148$ expressed in each tissue was normalized with that of $\beta$-actin. All qRT-PCR data are expressed as the means \pm SD using a testis value of 1 arbitrary unit $=100 \%$.

\section{In situ hybridization of $R N F 148$ mRNA in human testicular tissue}

In situ hybridizations were carried out as described elsewhere (Steger et al., 1998). Briefly, the obtained RT-PCR product of RNF148 was subcloned into a pGEM-T vector (Promega, San Luis Obispo, CA, USA). Digoxigenin (DIG)-labeled antisense and sense RNA probes were prepared using an RNA-DIG labeling kit (Roche, Basel, Switzerland). Hybridizations to testis sections were carried out at $37^{\circ} \mathrm{C}$ for $24 \mathrm{~h}$. Post-hybridization tissue samples were incubated overnight at $4^{\circ} \mathrm{C}$ with an anti-DIG Fab-antibody conjugated to alkaline phosphatase (Sigma-Aldrich Co.), and staining was visualized with nitroblue tetrazolium and 5-bromo-4-chloro-3-indolyl phosphate as substrates. Control incubations were performed using DIG-labeled complementary RNA sense probes.

\section{Western blotting analysis of RNF148}

Cell lysates were prepared, and western blotting was performed as described else- 
where (Liu et al., 2010a). A monoclonal antibody of anti-RNF148 (Sigma-Aldrich Co.) was used to detect RNF148, and an antibody against $\beta$-actin was used for loading normalization.

\section{Immunohistochemical analysis of RNF148 in human testis}

Immunohistochemical analysis of RNF148 in human testis was performed as described elsewhere (Liu et al., 2010a) using anti-RNF148 monoclonal primary antibody (1:500 dilution), and color signals were developed using an ABC staining kit (Pierce, Rockford, IL, USA). Pre-immune mouse serum was used as the primary antibody for the negative controls, and sections were counterstained with hematoxylin.

\section{Chromatin immunoprecipitation (ChIP) and quantitative PCR (qPCR)}

ChIP assays were performed with an agarose ChIP kit (Pierce). Briefly, HEK293T and HeLa cells were treated with $400 \mathrm{ng} / \mathrm{mL}$ TSA, AZA, or dimethyl sulfoxide (control) for $48 \mathrm{~h}$ and fixed with formaldehyde for 10 min. Cross-linked chromatin was digested with micrococcal nuclease at $37^{\circ} \mathrm{C}$ for $15 \mathrm{~min}$ to reduce the DNA fragment to less than 1000 base pairs. Chromatin was then precipitated via incubation with anti-acetylated histone $\mathrm{H} 3$ antibody (Millipore, Bedford, MA, USA). qPCR primers for regions 1, 2, and 3 located at the 5'-upstream sequence of RNF148 were as follows: -716F (5'-gtcacctccetggcttagaacc-3') and -577R (5'-atgtgctggcaaatactgagag-3'); $-287 \mathrm{~F} \quad\left(5^{\prime}\right.$-tttatctttgcetttgcttac-3') and $-195 \mathrm{R} \quad\left(5^{\prime}\right.$-agcettgggtttcttccttagt-3'); and $+119 \mathrm{~F}$ (5'-tttagtaatctgccgccaacaag-3') and +256R (5'-gaactatgcgtcgaaggggtaat-3'). qPCR was carried out using SYBR Premix Ex Taq II (Takara Biotech) with the following cycling parameters: $95^{\circ} \mathrm{C}$ for $1 \mathrm{~min} ; 9^{\circ} \mathrm{C}$ for $10 \mathrm{~s}, 52^{\circ} \mathrm{C}$ (regions 1 and 3 ) $/ 50^{\circ} \mathrm{C}$ (region 2), for $30 \mathrm{~s}$ and $72^{\circ} \mathrm{C}$ for $30 \mathrm{~s}$ for 40 cycles. As described by Luo et al. (2010), copy number was determined using a standard curve containing serial dilutions $\left(10^{6}-10^{0}\right.$ copies $)$ of the $R N F 148$ DNA amplicon. Samples were run in triplicate, and data were normalized to 5\% input DNA amplification after subtraction of the signals obtained from antibody isotype control. The ChIP-qPCR assay was repeated twice to confirm the reproducibility of results.

\section{RESULTS}

\section{RNF148 expression pattern}

To investigate the expression profile of RNF148 in human tissues and cells, we carried out PCR amplification with $16 \mathrm{cDNA}$ pools derived from various human tissues and cell lines. The results showed that $R N F 148$ mRNA was abundantly expressed in testes and detectable in pancreas in trace amounts (Figure 1A). qRT-PCR analysis confirmed that the expression in testis was more than 200-fold that in pancreas (Figure 1B). Western blot analysis of whole protein extracted from normal human testis and lung tissue further indicated that RNF148 was expressed only in human testes as a specific 30-kDa protein product (Figure 1C).

\section{Cellular localization of RNF148 in human testis}

In situ hybridization with gene-specific probes showed that $R N F 148$ mRNA was mainly 
present in the interstitial cells of human testicular tissue (Figure 2A-C). Furthermore, the results of immunohistochemical analysis were consistent with interstitial cellular distribution (Figure $2 \mathrm{D}-\mathrm{F}$ ).

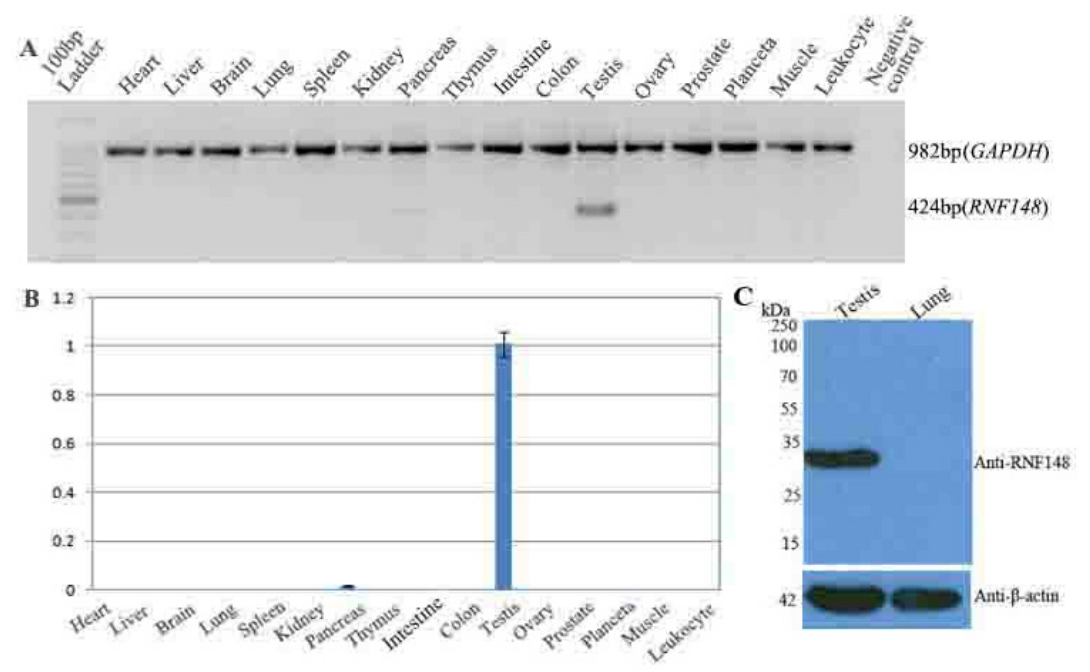

Figure 1. Expression pattern of $R N F 148$ gene in various human tissues and cells. A. Of the multiple human tissue samples that were tested, RNF148 mRNA expression was mainly amplified in human testis and few in pancreas by the regular RT-PCR analysis. The integrity of the examined cDNA was assessed by measuring the mRNA expression of $G 3 P D H$. B. Amount of RNF148 mRNA in multiple human tissue samples examined by qRT-PCR analysis. C. A single $30-\mathrm{kDa}$ band of RNF148 protein was detected in normal human testis by Western blot analysis using anti- RNF148 antibody as the primary antibody. RNF148 protein was present only in normal human testis.
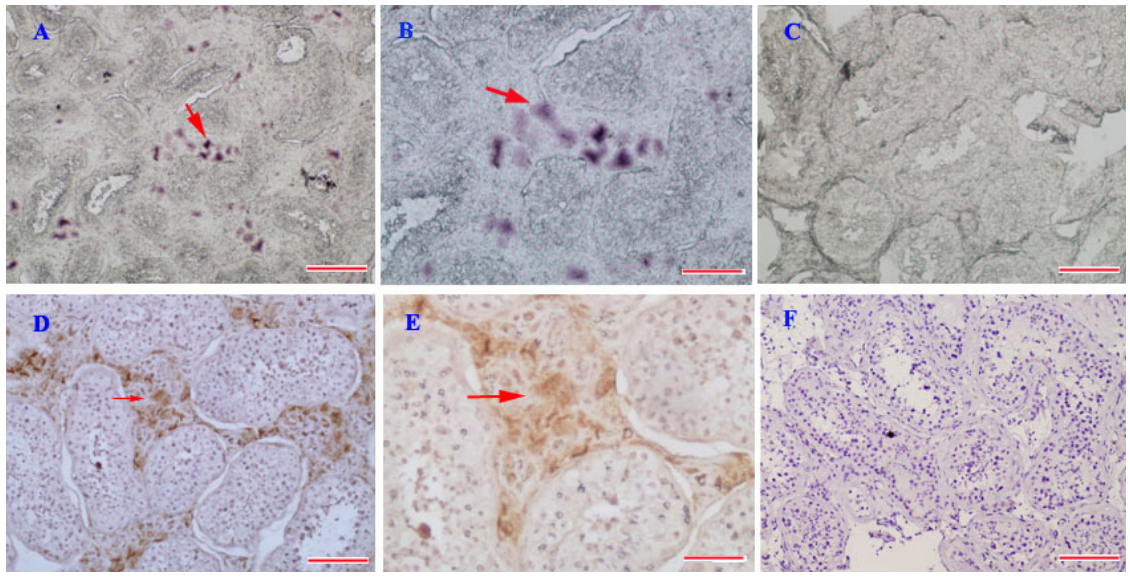

Figure 2. Localization of $R N F 148 \mathrm{mRNA}$ and protein in normal human testis by the analysis of in situ hybridization (AC) and immunohistochemistry (D-F). A. Signal of anti-sense RNA probe of RNF148 mRNA, the presence of RNF148 mRNA was in the testicular interstitial cells indicated by red arrows. B. Signal of A magnified for two times. C. Negative control of sense RNA probe of RNF148 mRNA. D. Signal of anti-RNF148 antibody, RNF148 protein was also present in the interstitial cells indicated by red arrows. E. Signal of D was magnified for two times. F. Negative control with preimmune mouse serum. Bars $=50 \mu \mathrm{m}$ in $\mathbf{A}, \mathbf{C}, \mathbf{D}$, and $\mathbf{F}$; bars $=100 \mu \mathrm{m}$ in $\mathbf{B}$ and $\mathbf{E}$. 


\section{TSA-promoted expression of RNF148 gene in HEK293T and HeLa cells}

HEK293T and HeLa cells without RNF148 gene expression were treated with TSA and AZA, respectively, to determine whether epigenetic modification regulates RNF148 expression. TSA activated the expression of RNF148 in both cell lines (Figure 3A), and the upregulation occurred in a time- and dose-dependent manner (see Figure 3A,B). Maximal induction of RNF148 mRNA was observed at $400 \mathrm{nmol} / \mathrm{mL}$ TSA and $48 \mathrm{~h}$ in HEK293T cells. RNF148 protein was also detected in both HEK293T and HeLa cells after TSA treatment (Figure 3C). However, $R N F 148$ expression was not affected by AZA treatment (see Figure 3A, C), indicating that DNA methylation may not be involved in the regulation of RNF148 expression.
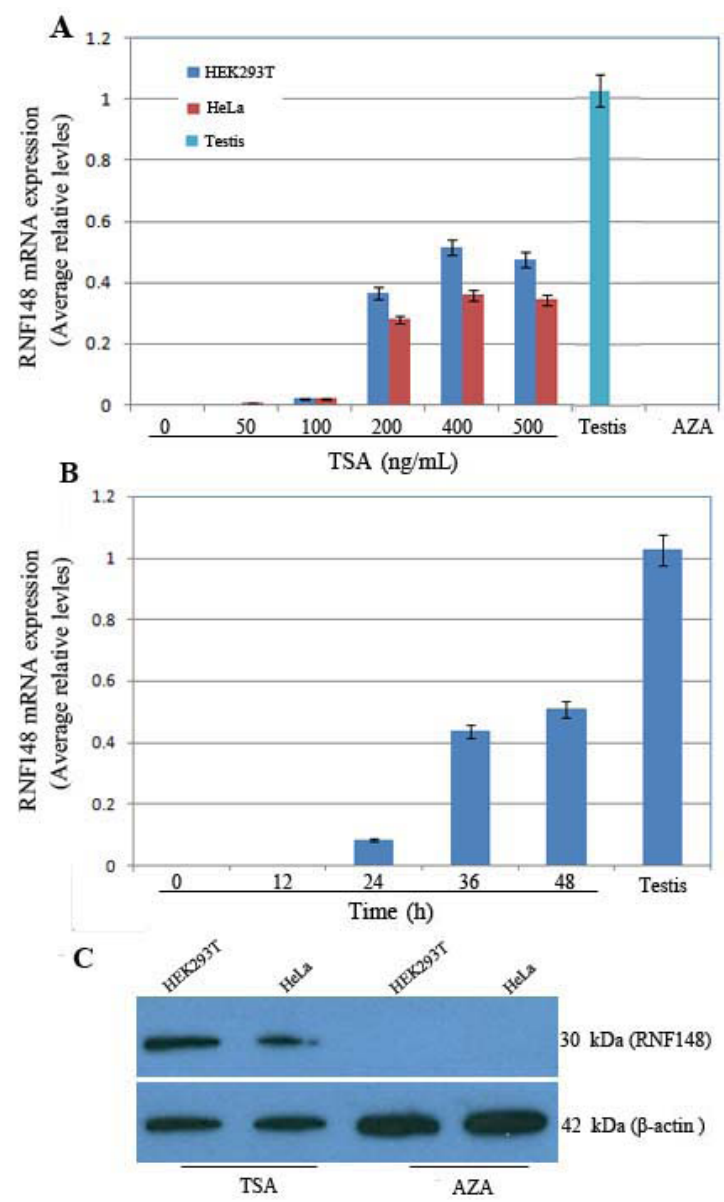

Figure 3. RNF148 mRNA expression in HEK293T and HeLa cells after TSA or AZA treatment. A. HEK293T and HeLa cells were treated with DMSO (0) or TSA at the designated concentrations $(50,100,200,300,400$, and $500 \mathrm{ng} / \mathrm{mL})$ or $5 \mu \mathrm{M}$ AZA for $48 \mathrm{~h}$ and evaluated for RNF148 mRNA expression. B. HEK293T cells were treated with $400 \mathrm{ng} / \mathrm{mL}$ TSA for $0,12,24,36$, or $48 \mathrm{~h}$ and evaluated for $R N F 148 \mathrm{mRNA}$ expression. The levels of $R N F 148 \mathrm{mRNA}$ were determined by qRT-PCR on isolated RNA. Results were expressed as arbitrary units after normalization to $\beta$-actin levels and are reported as means $\pm \mathrm{SD}$ of three independent experiments. The testis values were used as 1 arbitrary unit $=100 \%$. C. Western blotting analysis of RNF148 protein on the extract from HEK293T and HeLa cells after TSA or AZA treatment. 


\section{Acetyl-histone $\mathrm{H} 3$ binding to the promoter region of $\mathrm{RNF148}$}

To clarify the role of histone acetylation in the regulation of the $R N F 148$ gene expression, we examined acetylated histone $\mathrm{H} 3$ in the chromatin associated with the endogenous RNF148 gene promoter. ChIP-qPCR assays demonstrated that the levels of acetyl-histone H3 binding to regions 2 and 3 of $R N F 148$ were enhanced after TSA treatment (Figure 4A).

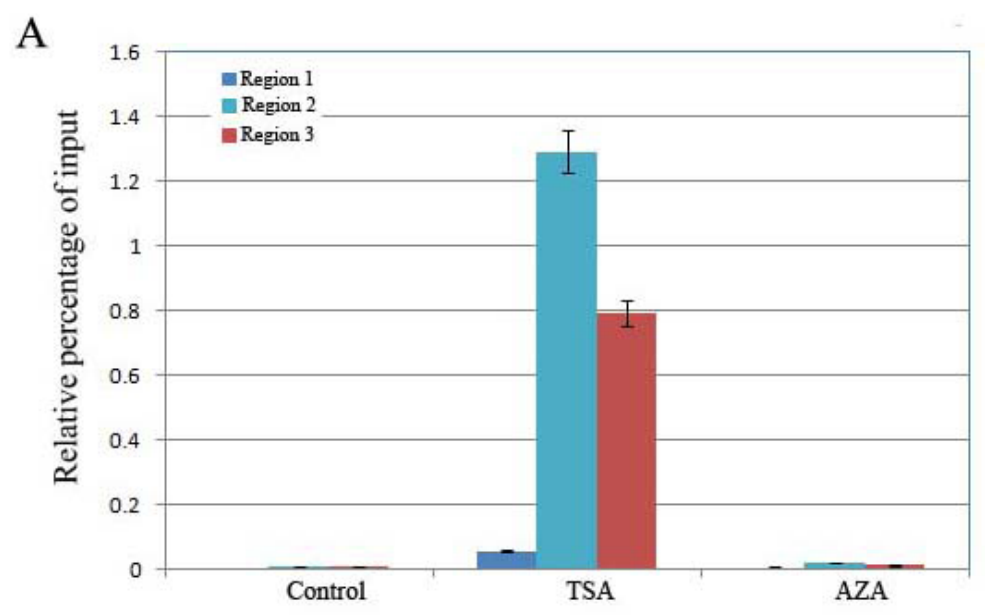

$\mathrm{B}$

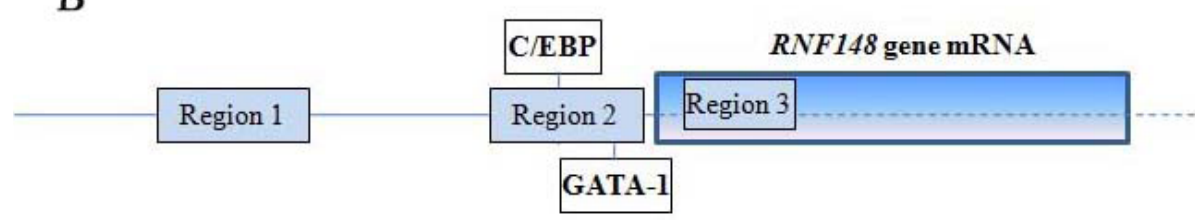

Figure 4. Acetyl-histone $\mathrm{H} 3$ binding to the promoter region of $R N F 148$ gene by the assay of ChIP-qPCR. A. Three regions were designed for the assay of ChIP-qPCR in the upstream sequence of $R N F 148$ gene. B. ChIP-qPCR of acetyl-histone $\mathrm{H} 3$ at the three regions. The amplification value from immunoprecipitated DNA was normalized to $5 \%$ input DNA and are reported as means \pm SD of three independent experiments.

\section{DISCUSSION}

In this study, we identified a novel human gene - RNF148 - that is abundantly present in the interstitial cells of testes. Currently, many testis-restrictive and testis-selective genes have been screened through cDNA microarray hybridization analyses (Andrews et al., 2000; Huang et al., 2005; Wang et al., 2010), and more than 400 genes essential for male fertility had been revealed using 3 main mouse models: knockout/knockin/gene-trapped, transgenic, and chemical-induced point mutant mice (O'Bryan and de Kretser, 2006; Matzuk and Lamb, 2008; Yatsenko et al., 2010; Jamsai and O'Bryan, 2011). Most of these testis genes are mainly present in germ cells, some are present in both germ cells and interstitial cells, and a few are restricted to interstitial cells. Our study is the first to find that RNF148 is located in the interstitial cells of human testicular tissues. In males, the interstitial cells are responsible for the production and secretion of testosterone in 
the presence of luteinizing hormone. Guais et al. (2004) have reported that rat Rnf130, which is homologous to RNF148, is regulated by luteinizing hormone/human chorionic gonadotropin in interstitial Leydig cells but not in germ cells. Whether male sex hormones regulate the expression of RNF148 and whether RNF148 is involved in the production of these sex hormones in interstitial cells is an intriguing question for further investigation.

Epigenetic mechanisms provide an organism with the molecular means to react promptly to environmental contingencies with stable alterations in gene expression (Zamudio et al., 2008). Studies have increasingly shown that histone modification plays important roles in the regulation of testis gene expression (Hiroi et al., 2004; Delaval et al., 2007; Steilmann et al., 2010). In this study, we observed that treatment with the histone deacetylase inhibitor TSA increased the binding of acetylated histone $\mathrm{H} 3$ to the $R N F 148$ promoter, which increased the expression of $R N F 148$. Searching the TRANSFAC 6.0 database (http://www.gene-regulation.com) we found several potential binding sites for transcription factors such as globin transcriptional factor 1 (GATA-1)and CCAAT/enhancer binding protein(C/EBP) in region 2 of the $R N F 148$ gene promoter (Figure $4 \mathrm{~B}$ ). The hypoacetylation of histone in the $R N F 148$ promoter region might inhibit the binding of these transcriptional factors and stop $R N F 148$ transcription. In addition to histone acetylation and deacetylation, other histone post-translational modifications such as methylation, phosphorylation, ubiquitylation, and sumoylation are of interest for future research on the regulation of $R N F 148$ expression.

Human $R N F 148$ encodes a polypeptide of 305 amino acids (aa), including a $\mathrm{C} 3 \mathrm{H} 2 \mathrm{C} 3$ type RING-H2 finger domain at the C-terminus from aa residues 258 to 299 . The aa sequence of the conserved $\mathrm{C} 3 \mathrm{H} 2 \mathrm{C} 3 \mathrm{RING}-\mathrm{H} 2$ finger domain has a high identity profile with that of human E3 ubiquitin ligases RNF128 (Anandasabapathy et al., 2003), RNF130 (Guais et al., 2006), and mouse Rnf133 (Nian et al., 2008) (Figure 5). Of these, RNF128 regulates T-cell tolerance and induces T-cell anergy through the ubiquitination activity of its RING finger domain (Nurieva et al., 2010; Whiting et al., 2011). Mouse testis-specific protein Rnf133 is mainly present in the cytoplasm of elongated spermatids and plays a role in sperm maturation through an endoplasmic reticulum-associated degradation pathway (Nian et al., 2008). Because RNF148 has primary structures that parallel those of E3 ubiquitin ligases, we also constructed several mutant transcripts of RNF148 with Flag- and HA-tag vectors to test whether RNF148 also functioned similarly as an E3 ubiquitin ligase. However, the expected proteins derived from RNF148 were not expressed in several cell lines (data not shown) for unclear reasons.

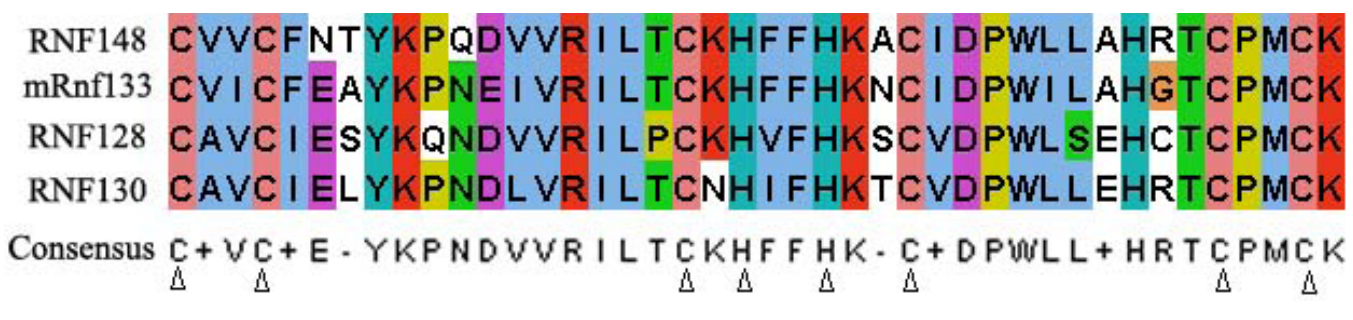

Figure 5. Alignment of the amino-acid sequences of RING-H2 domains of RNF148 and its homologues: RNF130, RNF128, and mRnf133. The sequence alignment was performed with the EBI ClustalW web tool (http://www.ebi. ac.uk/Tools/clustalw2/index.html). The conserve $\mathrm{C} 3 \mathrm{H} 2 \mathrm{C} 3$ sites were indicated by triangles.

In conclusion, we identified a novel interstitial gene, $R N F 148$, in human testicular tissue and detected that acetylation of histone $\mathrm{H} 3$ binding to the promoter region of RNF148 
activated its expression. We propose further research to explore the biological function of RNF148 as a RING-H2 finger protein and the role of other histone modifications on the regulation of RNF148 expression.

\section{ACKNOWLEDGMENTS}

Research supported by grants from the National High Technology Research and Development Program (Program "863") of the Ministry of Science and Technology of China (\#2001AA216091) and the Fundamental Research Funds for the Central Universities (\#2010SCU11025).

\section{REFERENCES}

Anandasabapathy N, Ford GS, Bloom D, Holness C, et al. (2003). GRAIL: an E3 ubiquitin ligase that inhibits cytokine gene transcription is expressed in anergic CD4+ T cells. Immunity 18: 535-547.

Andrews J, Bouffard GG, Cheadle C, Lu J, et al. (2000). Gene discovery using computational and microarray analysis of transcription in the Drosophila melanogaster testis. Genome Res. 10: 2030-2043.

Delaval K, Govin J, Cerqueira F, Rousseaux S, et al. (2007). Differential histone modifications mark mouse imprinting control regions during spermatogenesis. EMBO J. 26: 720-729.

Fuks F (2005). DNA methylation and histone modifications: teaming up to silence genes. Curr. Opin. Genet. Dev. 15: 490-495.

Guais A, Solhonne B, Melaine N, Guellaen G, et al. (2004). Goliath, a ring-H2 mitochondrial protein, regulated by luteinizing hormone/human chorionic gonadotropin in rat leydig cells. Biol. Reprod. 70: 204-213.

Guais A, Siegrist S, Solhonne B, Jouault H, et al. (2006). h-Goliath, paralog of GRAIL, is a new E3 ligase protein, expressed in human leukocytes. Gene 374: 112-120.

Hiroi H, Christenson LK, Chang L, Sammel MD, et al. (2004). Temporal and spatial changes in transcription factor binding and histone modifications at the steroidogenic acute regulatory protein (stAR) locus associated with stAR transcription. Mol. Endocrinol. 18: 791-806.

Huang X, Li J, Lu L, Xu M, et al. (2005). Novel development-related alternative splices in human testis identified by cDNA microarrays. J. Androl. 26: 189-196.

Iguchi N, Tobias JW and Hecht NB (2006). Expression profiling reveals meiotic male germ cell mRNAs that are translationally up- and down-regulated. Proc. Natl. Acad. Sci. U. S. A. 103: 7712-7717.

Jamsai D and O'Bryan MK (2011). Mouse models in male fertility research. Asian J. Androl. 13: 139-151.

Khalil AM, Boyar FZ and Driscoll DJ (2004). Dynamic histone modifications mark sex chromosome inactivation and reactivation during mammalian spermatogenesis. Proc. Natl. Acad. Sci. U. S. A. 101: 16583-16587.

Kimmins S and Sassone-Corsi P (2005). Chromatin remodelling and epigenetic features of germ cells. Nature 434: 583589.

Kimmins S, Kotaja N, Davidson I and Sassone-Corsi P (2004). Testis-specific transcription mechanisms promoting male germ-cell differentiation. Reproduction 128: 5-12.

Li Y, Sosnik J, Brassard L, Reese M, et al. (2011). Expression and localization of five members of the testis-specific serine kinase (Tssk) family in mouse and human sperm and testis. Mol. Hum. Reprod. 17: 42-56.

Liu YQ, Bai G, Zhang H, Su D, et al. (2010a). Human RING finger protein ZNF645 is a novel testis-specific E3 ubiquitin ligase. Asian J. Androl. 12: 658-666.

Liu Z, Zhou S, Liao L, Chen X, et al. (2010b). Jmjd1a demethylase-regulated histone modification is essential for cAMPresponse element modulator-regulated gene expression and spermatogenesis. J. Biol. Chem. 285: 2758-2770.

Luo W, Karpf AR, Deeb KK, Muindi JR, et al. (2010). Epigenetic regulation of vitamin D 24-hydroxylase/CYP24A1 in human prostate cancer. Cancer Res. 70: 5953-5962.

Matzuk MM and Lamb DJ (2008). The biology of infertility: research advances and clinical challenges. Nat. Med. 14: 1197-1213.

McCarrey JR, Geyer CB and Yoshioka H (2005). Epigenetic regulation of testis-specific gene expression. Ann. N. Y. Acad. Sci. 1061: 226-242.

Nian H, Zhang W, Shi H, Zhao Q, et al. (2008). Mouse RING finger protein Rnf133 is a testis-specific endoplasmic reticulum-associated E3 ubiquitin ligase. Cell Res. 18: 800-802. 
Nurieva RI, Zheng S, Jin W, Chung Y, et al. (2010). The E3 ubiquitin ligase GRAIL regulates T cell tolerance and regulatory $\mathrm{T}$ cell function by mediating $\mathrm{T}$ cell receptor-CD3 degradation. Immunity 32: 670-680.

O’Bryan MK and de Kretser D (2006). Mouse models for genes involved in impaired spermatogenesis. Int. J. Androl. 29: 76-89.

Payne C and Braun RE (2006). Histone lysine trimethylation exhibits a distinct perinuclear distribution in Plzf-expressing spermatogonia. Dev. Biol. 293: 461-472.

Russell LD, Ettlin RA, Sinha HAP and Clegg ED (1990). Mammalian Spermatogenesis. In: Histological and Histopathological Evaluation of the Testis (Russell LD, Ettlin RA, Sinha HAP and Clegg ED, eds). Cache River Press, St. Louis, 1-40.

Schultz N, Hamra FK and Garbers DL (2003). A multitude of genes expressed solely in meiotic or postmeiotic spermatogenic cells offers a myriad of contraceptive targets. Proc. Natl. Acad. Sci. U. S. A. 100: 12201-12206.

Steger K, Klonisch T, Gavenis K, Drabent B, et al. (1998). Expression of mRNA and protein of nucleoproteins during human spermiogenesis. Mol. Hum. Reprod. 4: 939-945.

Steilmann C, Cavalcanti MC, Bartkuhn M, Pons-Kühnemann J, et al. (2010). The interaction of modified histones with the bromodomain testis-specific (BRDT) gene and its mRNA level in sperm of fertile donors and subfertile men. Reproduction 140: 435-443.

Tse C, Sera T, Wolffe AP and Hansen JC (1998). Disruption of higher-order folding by core histone acetylation dramatically enhances transcription of nucleosomal arrays by RNA polymerase III. Mol. Cell Biol. 18: 4629-4638.

Wang L, Srivastava AK and Schwartz CE (2010). Microarray data integration for genome-wide analysis of human tissueselective gene expression. BMC Genomics 11 (Suppl 2): S15.

Wang X, He C, Moore SC and Ausio J (2001). Effects of histone acetylation on the solubility and folding of the chromatin fiber. J. Biol. Chem. 276: 12764-12768.

Whiting CC, Su LL, Lin JT and Fathman CG (2011). GRAIL: a unique mediator of CD4 T-lymphocyte unresponsiveness. FEBS J. 278: 47-58.

Yatsenko AN, Iwamori N, Iwamori T and Matzuk MM (2010). The power of mouse genetics to study spermatogenesis. J. Androl. 31: 34-44.

Zamudio NM, Chong S and O’Bryan MK (2008). Epigenetic regulation in male germ cells. Reproduction 136: 131-146. 